\title{
Phenotypic Analysis, Correlation Studies and Linkage Mapping of QTL for Traits Promoting Cultivation under Dry Direct Seeded Aerobic Conditions for the Development of Water-efficient High Yielding Rice Lines
}

\author{
A. KHARB*, S. JAIN and R.K. JAIN \\ Department of Molecular Biology, Biotechnology and Bioinformatics, College of Basic Sciences and \\ Humanities, CCS Haryana Agricultural University, Hisar 125004, India \\ (Received 11 March 2016; Accepted 12 April 2016; \\ Communicated by A. Aniol)
}

\begin{abstract}
Aerobic adaptation could be an important modification in the traditional rice to cope up with the increasing water scarcity problem. Identification of stable QTL for traits promoting adaptation to aerobic conditions can facilitate the development of water-efficient aerobic rice varieties with better yields. Filial and backcross populations derived from the crosses between high-yielding low-land (HKR47) and aerobic (MAS26) indica rice varieties, were evaluated for various physio-morphological traits including root traits (in case of net house evaluation). Under aerobic field conditions, grain yield per plant showed significant positive correlation with plant height, effective number of tillers/plant and panicle length in all the populations. Grain yield per plant also showed positive correlation with root length in both filial populations and with fresh and dry root weight in $\mathrm{F}_{2}$ population. Two parental rice varieties displayed polymorphism at 125 of the 803 SSR loci, which were used to map the QTL associated with traits promoting aerobic adaptation. A total of 14 QTL were detected, 10 of them were identified on chromosome 8. Study led to the identification of a number of promising plants with higher grain yield, better root length/biomass under managed aerobic conditions and possessing most of the identified QTL.
\end{abstract}

Keywords: rice, aerobic, molecular markers, root traits, QTL

\section{Introduction}

Rice (Oryza sativa L.) is life for more than half of humanity. It is the staple food of more than $60 \%$ of the world's population and demand is expected to continue growing as population increases. Globally rice is grown over an area of about 164.7 million ha with an annual production of 745.7 million tonnes (FAO 2013). In agriculture, rice is the single biggest user of water. Conventional rice production ecosystems (puddled transplanted) require an average of 2500-3000 liters of water to produce $1 \mathrm{~kg}$ of rice, which is 2-3 times more as compared to other cereals (Tuong et al. 2005). However, the worsening scarcity of water is posing a major threat to the sustainability of the irrigated rice ecosys-

\footnotetext{
*Corresponding author; E-mail: kharb.anju@gmail.com
} 
tem. Water stress during the cropping season directly affects grain yield (GY), which is particularly devastating at the reproductive stage (Venuprasad et al. 2009). As agricultural water scarcity is increasing day by day, we need to find out water efficient rice production strategies.

It has been reported that a deep and thick root system in the upland rice lines (japonicas) is largely responsible for their tolerance to water limited conditions (Shen et al. 2001). Aerobic rice has an efficient root system in terms of density, length, thickness and greater root penetration (Clark et al. 2000) and hence, can save as much as 50\% of irrigation water in comparison to lowland rice (Parthasarathi et al. 2012) and is highly productive. It requires irrigation only when the soil water potential reaches below the threshold capacity of field (Belder et al. 2005). Studies have shown the presence of high genetic variability for many physio-morphological traits controlling water stress response in rice (Manickavelu et al. 2006). Progress has been made in identifying QTLs for root traits and grain yield, however, progress in breeding for water stress/drought tolerance has been slow. We need to identify stable QTL for traits promoting dry direct seeded rice cultivation under aerobic conditions across environments which can aid in marker assisted selection and development of efficient varieties possessing good yield potential under water limited conditions. The present study aimed at investigating genetic variation, finding correlation of grain yield under water limited conditions with other traits and identifying QTL for traits promoting adaptation to aerobic cultivation conditions.

\section{Materials and Methods}

\section{Plant material}

HKR47, a low-land high yielding indica rice variety unadapted to cultivation in aerobic conditions (used as female) and MAS26, an aerobic rice variety (used as male) were selected as parents to develop mapping populations in the present study. MAS26 is an aerobic rice variety developed at University of Agricultural Sciences, Bangalore, from a cross between upland rice variety and low-land rice variety to combine the drought-resistant characteristics of upland rice (better root system and less water requirement) with the high-yielding traits of low-land rice (grown in irrigated, flooded fields). The $\mathrm{F}_{2}$ and $\mathrm{F}_{3}$ (developed by selfing) crops were raised in 2012 and 2013, respectively, in the net house at CCS HAU, Hisar as well as in the field at CCS HAU Rice Research Station, Kaul, Kaithal, India. In the net house, seeds were grown in the pots (one plant per pot) and were irrigated with one litre of water for the first fifteen days, then with one litre after every third day and second day pre-panicle emergence and post-panicle emergence, respectively. After every fifteenth day, the pots were irrigated with full-strength yoshida nutrient solution for the first 30 days, and with half-strength yoshida nutrient solution thereafter. In field, seeds were grown at an approximately $2 \mathrm{~cm}$ depth in dry-ploughed and harrowed aerobic plots in rows of $2.5 \mathrm{~m}$ length with plant to plant spacing of $15 \mathrm{~cm}$ and row to row spacing of $20 \mathrm{~cm}$. The plants were irrigated at an interval of 5 days up to panicle emer- 
gence and at an interval of 3 days after panicle emergence. Backcross generations, $\mathrm{BC}_{2} \mathrm{~F}_{1}$ and $\mathrm{BC}_{2} \mathrm{~F}_{2}$ (HKR47 as recurrent parent) were also raised in the field.

\section{Traits measurement and phenotypic analysis}

At physiological maturity, data was recorded on various agronomic traits; plant height $(\mathrm{cm})$, effective number of tillers per plant, panicle length $(\mathrm{cm}), 1000$-grain weight $(\mathrm{g})$, length/breadth ratio and grain yield $(\mathrm{g})$. Length/breadth ratio was recorded using digital Vernier Caliper. For grain weight determinations, 100-grain (dehusked) samples were taken from the harvested grains to compute 1000-grain weight. In net house experiment, the data was also recorded on root length $(\mathrm{cm})$, fresh and dry root weight $(\mathrm{g})$ and root thickness $(\mathrm{cm})$. For dry root weight, roots were dried in an oven set to low heat $\left(50^{\circ} \mathrm{C}\right)$ overnight, cooled in a dry environment and then measured. The thickness of the root crown was measured using a Vernier Caliper. The data was subsequently analyzed using OPSTAT (http://hau.ernet.in/opstat.html) to determine the variability and phenotypic (r) correlation coefficient analysis. Phenotypic correlation coefficients were tested against standardized tabulated significant value of $r$ with $(n-2)$ degree of freedom as per the procedure described by Fisher and Yates (1963).

\section{Genotypic analysis and QTL mapping}

QTL identification and mapping for the traits promoting adaptation to aerobic cultivation conditions was done using selected $94 \mathrm{~F}_{2}$ plants (net house) and $94 \mathrm{~F}_{3}$ plants (field + net house), displaying the entire range of variation for traits under study. DNA was isolated from the leaf tissues using CTAB DNA isolation procedure of Saghai-Maroof et al. (1984). A total of 803 SSR markers widely distributed on 12 rice chromosomes were analyzed for polymorphism in two parental rice genotypes (HKR47 and MAS26); of these, 125 showed polymorphism (Table S1*). These markers were obtained based on published rice genome maps (IRGSP 2005). The DNA fingerprint database was prepared using 125 and 88 polymorphic SSR markers for $\mathrm{F}_{2}$ and $94 \mathrm{~F}_{3}$ generations, respectively. PCR products were resolved by ethidium bromide stained $4 \%$ polyacrylamide gel electrophoresis (PAGE). Amplified products from SSR analysis were scored visually for presence or absence of bands; data was scored as 1 (present) and 0 (absent) for each of the SSR locus. The $0 / 1$ matrix was used to calculate genetic similarities between the genotypes by the similarity coefficient based on the proportion of shared electromorphs using 'Simqual' sub-program of NTSYS-PC (Version 2.02 Exeter Software, Setauket, NY, USA) package (Rohlf 1993). The resultant distance matrix data was used for two-dimensional scaling of rice genotypes. QTL analysis was done by using Win QTL cartographer version 2.5 (Wang et al. 2012) via composite interval mapping (CIM). The threshold log likelihood ratio (LOD) score was estimated empirically with 300 times permutations at a significant level of $\mathrm{p}=0.05$.

\footnotetext{
*Further details about the Electronic Supplementary Material (ESM) can be found at the end of the article.
} 


\section{Results}

The aerobic indica rice variety (MAS26) performed better than the low-land high yielding indica rice variety (HKR47) in terms of yield under dry direct-seeded aerobic cultivation conditions in both environments (net house as well as field) and in both generations $\left(\mathrm{F}_{2}\right.$ and $\left.\mathrm{F}_{3}\right)$ (Tables 1 and 2$)$. Root length, root biomass and root thickness were also found to be better in aerobic rice variety (MAS26) than those of the susceptible parent (HKR47) in case of population grown in net house.

\section{Phenotypic analysis}

In $\mathrm{F}_{2}$ population, field evaluation (evaluation of crop grown in field) revealed wide variation for plant height, effective numbers of tillers per plant, panicle length, grain length/ breadth ratio, thousand-grain weight and grain yield per plant (2.6-50.9 g) (Table 1). Correlation study displayed that grain yield/plant showed a significant positive correlation with plant height $(0.261, \mathrm{p}=0.01)$, effective number of tillers/plant $(0.830, \mathrm{p}=0.01)$, panicle length $(0.345, \mathrm{p}=0.01)$ and 1000 -grain weight $(0.180, \mathrm{p}=0.01)$ (Table $\mathrm{S} 2) . \mathrm{F}_{2}$ net house evaluation (evaluation of crop grown in net house) revealed a significant and positive correlation with effective number of tillers/plant, panicle length, root length, fresh root weight, dry shoot weight and dry root weight as mentioned in our previous study (Kharb et al. 2015).

In $\mathrm{F}_{3}$ population, five plants per line were evaluated. In field evaluation, yield per plant showed positive correlation with plant height, effective number of tillers/plant and panicle length. Thousand-grain weight showed a positive correlation with plant height, panicle length and grain length/breadth ratio (Table S2). In net house evaluation, phenotypic correlation coefficient analysis showed a positive correlation $(0.351, p=0.05)$ between root length and grain yield per plant. In this population, grain yield/plant also showed positive correlation with plant height, effective number of tillers/plant, panicle length and 1000 -grain weight. Root thickness revealed a positive correlation with fresh root weight $(0.854, \mathrm{p}=0.01)$, dry root weight $(0.885, \mathrm{p}=0.01)$ and yield/plant $(0.279, \mathrm{p}=0.05)$.

Table 1. Mean and range for various agronomic and root traits in (HKR $47 \times$ MAS26) $\mathrm{F}_{2}$ population grown in field under aerobic conditions

\begin{tabular}{|l|c|c|c|c|}
\hline \multirow{2}{*}{ Traits } & \multirow{2}{*}{ HKR 47 } & \multirow{2}{*}{ MAS26 } & \multicolumn{2}{c|}{ HKR 47 $\times$ MAS26 $\mathrm{F}_{2}$ population } \\
\cline { 4 - 5 } & & & Mean & Range \\
\hline Plant height (cm) & $85.7 \pm 1.19$ & $77.4 \pm 0.33$ & $87.7 \pm 0.4$ & $63.5-116.8$ \\
\hline Effective no of tillers/plant & $9.0 \pm 1.04$ & $13.0 \pm 0.67$ & $9.08 \pm 0.2$ & $3-25$ \\
\hline Panicle length (cm) & $19.3 \pm 0.46$ & $18.8 \pm 0.43$ & $21.4 \pm 0.1$ & $17.3-26.9$ \\
\hline Length/Breadth ratio & $3.11 \pm 0.23$ & $3.40 \pm 0.30$ & $2.95 \pm 0.0$ & $1.7-3.8$ \\
\hline 1000-grain weight (g) & $16.5 \pm 0.63$ & $18.4 \pm 1.06$ & $23.3 \pm 0.2$ & $8.1-29.9$ \\
\hline Yield per plant (g) & $17.1 \pm 1.18$ & $21.9 \pm 0.38$ & $16.6 \pm 0.5$ & $2.6-50.9$ \\
\hline
\end{tabular}


Effective number of tillers/plant had a positive correlation with plant height, fresh root weight, dry root weight and root thickness. Root length had significant positive correlation with plant height and panicle length (Table S3).

In $(\mathrm{HKR} 47 \times \mathrm{MAS} 26) \times \mathrm{HKR} 47 \mathrm{BC}_{2} \mathrm{~F}_{2}$ population, yield per plant showed positive correlation with plant height, effective number of tillers/plant, panicle length and thousand-grain weight. Thousand-grain weight showed positive correlation with plant height and panicle length (Table S4).

\section{Molecular marker analysis}

In $\mathrm{F}_{2}$ generation, QTL mapping was done in the net house population and CIM analysis revealed a total of six QTL, three QTL for effective number of tillers per plant, one for thousand-grain weight, one for grain yield/plant and one for root length, using 125 polymorphic markers as reported in our previous study (Kharb et al. 2015).

In $\mathrm{F}_{3}$ generation, a DNA fingerprint database of selected 52 and $42 \mathrm{HKR} 47 \times$ MAS26 $\mathrm{F}_{3}$ plants from field and net house, respectively (displaying the entire range of variation

Table 2. Mean and range for various agronomic and root traits in (HKR $47 \times$ MAS26) $\mathrm{F}_{3}$ population grown under aerobic conditions

\begin{tabular}{|c|c|c|c|c|}
\hline \multirow{2}{*}{ Traits } & \multirow{2}{*}{ HKR 47} & \multirow{2}{*}{ MAS26 } & \multicolumn{2}{|c|}{ HKR $47 \times$ MAS2 $6 \mathrm{~F}_{3}$ population } \\
\hline & & & Mean & Range \\
\hline \multicolumn{5}{|l|}{ In field } \\
\hline Plant height $(\mathrm{cm})$ & $100.3 \pm 0.54$ & $97.1 \pm 0.42$ & $95.1 \pm 0.5$ & $67.5-130.1$ \\
\hline Effective no of tillers/plant & $9.8 \pm 0.86$ & $11.9 \pm 1.22$ & $7.0 \pm 0.2$ & $1-20$ \\
\hline Panicle length $(\mathrm{cm})$ & $21.1 \pm 0.21$ & $23.3 \pm 0.26$ & $21.6 \pm 0.1$ & $14.0-30.2$ \\
\hline Length/Breadth ratio & $3.16 \pm 0.12$ & $3.53 \pm 0.11$ & $3.23 \pm 0.1$ & $2.49-4.12$ \\
\hline 1000 -grain weight (g) & $21.4 \pm 0.21$ & $24.5 \pm 0.18$ & $23.3 \pm 0.1$ & $18.4-39.0$ \\
\hline Yield per plant (g) & $17.4 \pm 0.88$ & $18.0 \pm 1.78$ & $11.4 \pm 0.3$ & $1.22-26.5$ \\
\hline \multicolumn{5}{|l|}{ In net house } \\
\hline Plant height $(\mathrm{cm})$ & $74.2 \pm 0.11$ & $87.4 \pm 0.51$ & $73.5 \pm 2.0$ & $30.8-95.5$ \\
\hline Effective no of tillers/plant & $5.5 \pm 1.51$ & $4.8 \pm 0.58$ & $3.80 \pm 0.3$ & $1-12$ \\
\hline Panicle length $(\mathrm{cm})$ & $18.0 \pm 0.37$ & $22.2 \pm 0.35$ & $21.4 \pm 0.4$ & $11.2-26.5$ \\
\hline Length/Breadth ratio & $2.81 \pm 0.07$ & $3.02 \pm 0.24$ & $2.90 \pm 0.0$ & $2.37-3.64$ \\
\hline 1000-grain weight (g) & $15.1 \pm 0.22$ & $18.5 \pm 0.52$ & $16.6 \pm 0.7$ & $1.6-23.3$ \\
\hline Yield per plant (g) & $3.09 \pm 1.04$ & $5.97 \pm 0.73$ & $3.80 \pm 0.4$ & $0.22-11.2$ \\
\hline Root length $(\mathrm{cm})$ & $38.6 \pm 0.82$ & $53.5 \pm 1.02$ & $49.0 \pm 1.3$ & $16.8-70.4$ \\
\hline Fresh root weight $(\mathrm{g})$ & $12.5 \pm 1.30$ & $24.8 \pm 0.71$ & $12.0 \pm 1.2$ & $0.4-41.7$ \\
\hline Dry root weight $(\mathrm{g})$ & $2.23 \pm 1.27$ & $4.34 \pm 0.29$ & $2.68 \pm 0.3$ & $0.13-10.9$ \\
\hline Root thickness (cm) & $1.82 \pm 0.75$ & $1.95 \pm 1.10$ & $1.94 \pm 0.1$ & $1.1-4.2$ \\
\hline
\end{tabular}




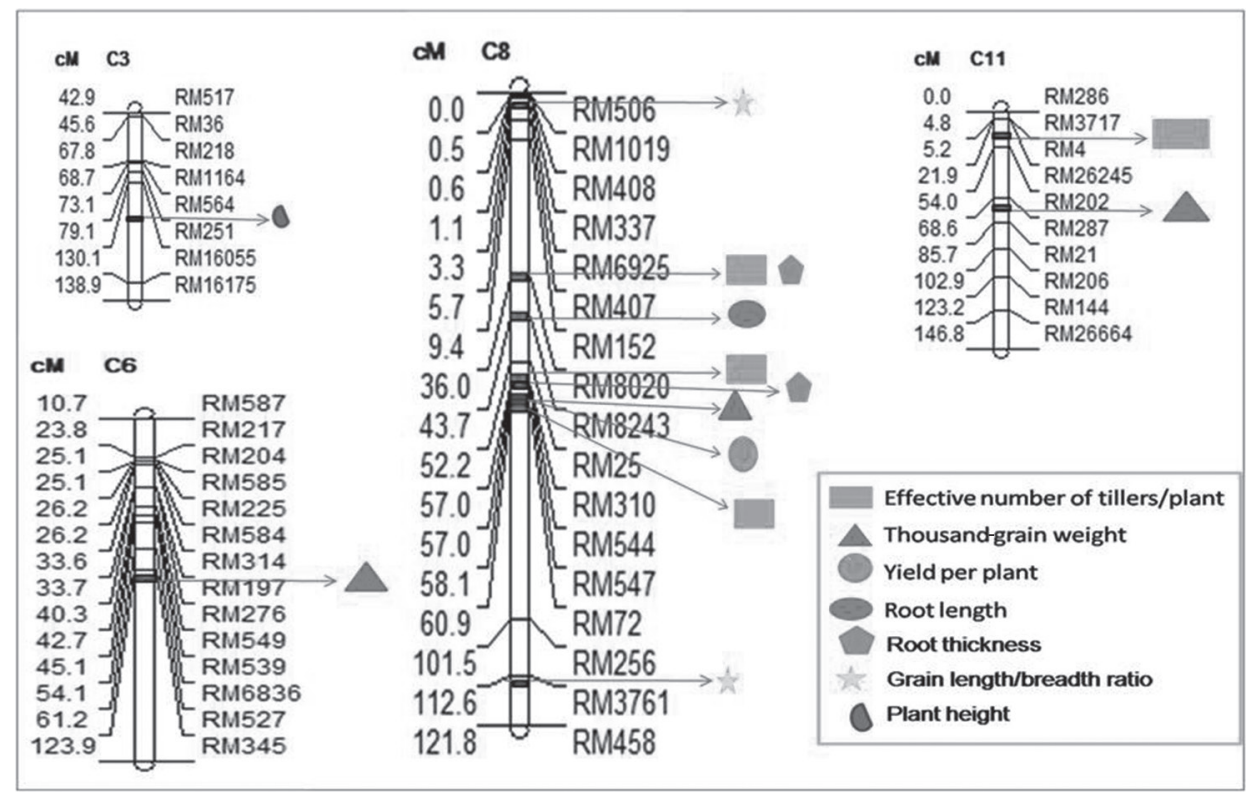

Figure 1. The genetic linkage map and the chromosomal locations of quantitative trait loci (QTL) identified via microsatellite marker analysis in both generations $\left(F_{2}\right.$ in net house, $F_{3}$ in net house and $F_{3}$ in field)

in agronomic traits), was prepared using 88 SSR markers. In field evaluation, a total of 198 alleles were identified; twenty of 88 SSR markers amplified recombinant (new) alleles which were different to those present in two parental rice varieties. On an average, $50.64 \%$ alleles were from HKR47 and 49.36\% alleles were from MAS26 in all $52 \mathrm{~F}_{3}$ plants. Two dimensional PCA scaling exhibited that $\mathrm{F}_{3}$ plants were interspersed between the two parental lines with an inclinational towards MAS26 (Fig. S1). Composite interval mapping (CIM) analysis revealed two QTL (Table 3, Fig. 1). $\mathrm{qPN}_{11.1}$, a QTL for effective number of tillers per plant, was mapped on chromosome 11 and $\mathrm{qLB}_{8.1}$, a QTL for length/ breadth ratio of grain, on chromosome 8 with percent phenotypic variation of $6.7 \%$ and $10.3 \%$, respectively. RM3761 showed significant association with grain length/breadth ratio. Both of the QTL identified in this study, with an additive effect of 0.260 and 0.076 , respectively, were from HKR47.

In $\mathrm{F}_{3}$ net house evaluation, eight of 88 SSR markers amplified recombinant (new) alleles which were different to those present in two parental rice varieties. A total of 184 alleles were identified in the selected $42 \mathrm{~F}_{3}$ plants. Two-dimensional PCA scaling exhibited the distribution of most of the plants towards MAS26 (Fig. S2). CIM analysis revealed a total of six QTL; one for plant height, one for grain length/breadth ratio, two for thousand-grain weight and two for root thickness (Table 3, Fig. 1). Six QTL identified were mapped on chromosome $3\left(\mathrm{qPH}_{3.1}\right.$ at map position $\left.93.2 \mathrm{cM}\right)$, chromosome 6 $\left(\mathrm{qTGW}_{6.1}\right.$ at map position $\left.61.6 \mathrm{cM}\right)$, chromosome $8\left(\mathrm{qLB}_{8.2}, \mathrm{qRT}_{8.1}\right.$ and $\mathrm{qRT}_{8.2}$ at map positions $2.1,36.0$ and $56.2 \mathrm{cM}$, respectively) and chromosome $11\left(\mathrm{qTGW}_{11.1}\right.$ at map 


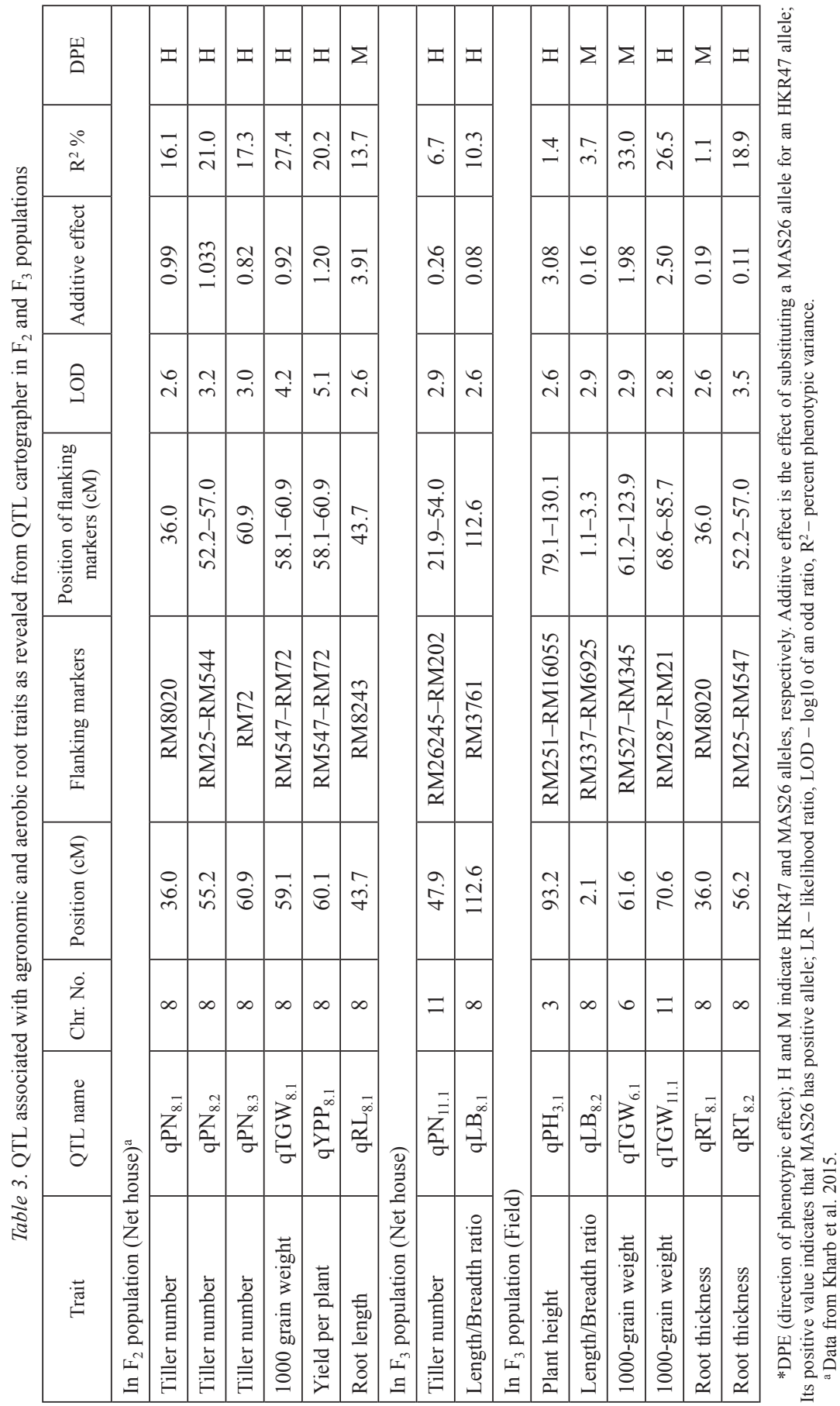


position 70.6). The QTL qPH $\mathrm{QPH}_{3.1}, \mathrm{qLB}_{8.2}, \mathrm{qTGW}_{6.1}, \mathrm{qTGW}_{11.1}, \mathrm{qRT}_{8.1}$ and $\mathrm{qRT}_{8.2}$ accounted for $1.4,3.7,33,26.5,1.1,18.9 \%$ phenotypic variance. Three QTL, $\mathrm{qPH}_{3.1}, \mathrm{qTGW}_{11.1}$ and $\mathrm{qRT}_{8.1}$ were from HKR47 and the remaining three QTL $\left(\mathrm{qLB}_{8.2}, \mathrm{qTGW}_{6.1}\right.$ and $\left.\mathrm{qRT}_{8.1}\right)$ were from MAS26.

\section{Discussion}

The increasing water shortage has led to the development of aerobic rice system, which is water-efficient and possesses high per drop productivity. Although under conventional flooded conditions, yield potential of aerobic rice genotypes are lower than the low-land rice varieties but aerobic rice cultivation is quite promising where water is too scarce to grow low-land rice (James Martin et al. 2007; Gandhi et al. 2011). In the present study as well, under dry direct-seeded aerobic conditions, aerobic rice variety (MAS26) yielded higher than lowland indica variety (HKR47) in all the environments and generations.

A dynamic root system is known to regulate the amount of water available to the plant depending on its distribution in the soil; consequently, studying the root system is significantly important to fight against the water scarce conditions. In aerobic rice varieties, roots grow deeper and more profusely in comparison to shallow roots in low-land rice varieties, which help in better absorption of water thereby eliminating the need for water logging (Clark et al. 2000). In the present study, root system in aerobic rice variety was found better than irrigated lowland variety in terms root length, root weight and root thickness, under aerobic soil conditions. Similar results were obtained by Amudha et al. (2009) and James Martin et al. (2007). Root length, dry root weight and root thickness were found to be $39-47 \%, 37-84 \%$ and $7-16 \%$ higher in MAS26 than HKR47, respectively. In the $\mathrm{F}_{2}$ and $\mathrm{F}_{3}$ segregating populations, root morphology evaluation showed that 88 and 70 plants in $\mathrm{F}_{2}$ and 28 and 14 plants in $\mathrm{F}_{3}$ generation had better root length and dry root weight than the better parent MAS26, respectively. Increased root length allows roots to penetrate hard pans characteristic of some lowlands, thickness and density improves water uptake by producing more and larger root branches (Ingram et al. 1994).

Yield attributes and root traits are two important considerations for the development of water efficient rice varieties with higher yield, thus, phenotypic correlation analysis was done to assess the association between these traits. Yield per plant showed a significant positive correlation with plant height, effective number of tillers per plant and panicle length in all the populations. Nagaraju et al. (2013) also reported that number of grains per panicle, total number of productive tillers per plant, kernel L/B ratio, and panicle length showed highly significant positive association with grain yield per plant. Reports also show significant association between yield and plant height, panicle number and number of tillers (Girish et al. 2006).

In the present study, yield per plant showed significant and positive correlation with root length, fresh root weight and dry root weight in $F_{2}$ population and with root length and root thickness in $\mathrm{F}_{3}$ generation. Venuprasad et al. (2002) reported a significant positive correlation between root length and grain yield. Kanbar et al. (2009) found that root dry weight (RDW) is positively associated with grain yield and yield morphological 
traits. Positive association between yield and root traits clearly indicates the importance of root system in plant adaptability to water limited conditions.

Linkage mapping of genes/QTL detects marker-trait associations and aids in marker aided selection (MAS) to efficiently select progenies carrying alleles for target traits. In the present study, a total of 22 new recombinant alleles (different that those in parent rice varieties) were identified in $\mathrm{F}_{3}$ plants. There are a variety of potential reasons for the formation of non-parental bands, including recombination or mutation in the simple-sequence repeat region, residual heterozygosity in parental lines, or chromosomal aberrations resulting from rearrangements and transposons (Ramekar et al. 2015).

A total of 14 QTL were identified on chromosomes 3, 6, 8 and 11; six in $\mathrm{F}_{2}$ population (Kharb et al. 2015) while eight in $\mathrm{F}_{3}$ population (present study) (Table 3, Fig. 1). Of the 14 QTL identified, 10 QTL were localized on chromosome 8, of which, six QTL were located with a region of $24.9 \mathrm{cM}$. Earlier studies have also reported QTL for root length and other root traits on chromosome 8 (Courtois et al. 2003; Li et al. 2005; Qu et al. 2008). Sandhu et al. (2013) reported three QTL for root length in the MASARB25 $\times$ Pusa Basmati 1460 and HKR47 $\times$ MAS26 mapping populations close to the root QTL identified. Sandhu et al. (2013 and 2014) and Vikram et al. (2012) reported QTL for grain yield close to the QTL identified for grain yield per plant. Other reports are also available for yield QTL on chromosome 8 (Hanamaratti et al. 2007; Bernier et al. 2008). In the present study, two QTL were identified for root thickness ( $\mathrm{qRT}_{8.1}$ and $\mathrm{qRT}_{8.2}$ at 36.0 and $56.2 \mathrm{cM}$, respectively) on chromosome 8. Kamoshita et al. (2002) also reported three QTL for root thickness at 3.8, 32.8 and $50.7 \mathrm{cM}$ using recombinant inbred lines (RILs) from a lowland indica cross. Sandhu et al. (2014) reported a grain yield QTL (at $56.3 \mathrm{cM}$ ) in vicinity of root thickness QTL (qRT ${ }_{8.2}$ ). Sandhu et al. (2013) reported two roots length QTL close to the root thickness QTL identified. It must be noted that the QTL mapped using $\mathrm{F}_{2}$ mapping population, were not identified/mapped using $\mathrm{F}_{3}$ data. The number of QTL detected in each study depends on the genetic diversity among parents, population size, population genotype, environment and the number of markers tested (Brondani et al. 2002).

The present investigation was focused on the goal of improving water efficiency along with superior agronomic and high yield characteristics in rice using conventional breeding and marker assisted selection techniques in combination. Based on the phenotypic and genotypic evaluation, few promising $\mathrm{F}_{3}$ plants were selected to carry forward them for the development of water efficient lines. Selected plants possessed better agronomic traits and had QTL, identified in this study, at variable frequencies. Of the selected plants, $20 \%$ plants had maximum number of QTL identified (13), 15\% plants had 12 QTL and $10 \%$ plants had 11 QTL in homozygous or heterozygous state. The $55 \%$ plants with higher yield also possessed yield QTL. All the plants, selected on the basis of net house evaluation (with better root length) possessed $\mathrm{qRL}_{8.1}$ in homozygous or heterozygous state. In case of backcross populations also, promising $\mathrm{BC}_{2} \mathrm{~F}_{2}$ plants were selected on the basis of yield and yield components. There is a need to develop rice varieties that will produce acceptable yields in water-limited environments. Development of a recombinant inbred line population from this diverse cross is in progress for further analysis and marker assisted selection. 


\section{References}

Amudha, K., Thiyagarajan, K., Robin, S., Prince, S.J.K., Poornima, R., Suji, K.K. 2009. Heterosis under aerobic condition in rice. Electron. J. Plant Breed. 1:769-775.

Belder, O., Bouman, B.A.M., Spiertz, J.H.J., Peng, S., Castaneda, A.R., Visperas, R.M. 2005. Crop performance, nitrogen and water use in flooded and aerobic rice. Plant Soil 273:167-182.

Bernier, J., Kumar, A., Venuprasad, R., Spaner, D., Verulkar, S., Mandal, N.P., Sinha, P.K., Peeraju, P., Dongre, P.R., Mahto, R.N., Atlin, G. 2008. Characterization of the effect of a QTL for drought resistance in rice, qt112.1, over a range of environments in the Philippines and eastern India. Euphytica 166:207-217.

Brondani, C., Rangel, P.H.N., Brondani, R.P.V., Ferreira, M.E. 2002. QTL Mapping and introgression of yieldrelated traits from Oryza glumaepatula to cultivated rice (Oryza sativa) using microsatellite markers. Theor. Appl. Genet. 104:1192-1203.

Clark, L.J., Aphale, S.L., Barraclough, P.B. 2000. Screening the ability of rice roots to overcome the mechanical impedance of wax layers: Importance of test conditions and measurement criteria. Plant Soil 219:187-196.

Courtois, B., Shen, L., Petalcorin, W., Carandang, S., Mauleon, R., Li, Z. 2003. Locating QTLs controlling constitutive root traits in the rice population IAC $165 \times$ Co39. Euphytica 134:335-345.

FAO 2013. Statistics. http://faostat3.fao.org/browse/Q/QC/E.

Fisher, R.A., Yates, F. 1963. Statistical tables for biological, agricultural and medicinal research, $6^{\text {th }}$ edn. Oliver and Boyd. Edinburgh, UK. 63. p.

Gandhi, V.R., Rudresh, N.S., Shivamurthy, M., Hittalmini, S. 2011. Performance and adoption of new aerobic rice variety MAS 946-1 (Sharada) in southern Karnataka. Karnataka J. Agric. Sci. 25:5-8.

Girish, T.N., Gireesha, T.M., Vaishali, M.G., Hanamareddy, B.G., Hittalmani, S. 2006. Response of a new IR50/ Moroberekan recombinant inbred population of rice (Oryza sativa L.) from an indica $\times$ japonica cross for growth and yield traits under aerobic conditions. Euphytica 152:149-161.

Hanamaratti, N.G. 2007. Identification of QTL for physiological and productivity traits under drought stress and stability analysis in upland rice (Oryza sativa L.). Dissertation for Ph.D. University of Agricultural Sciences. Dharwad, Karnataka, India.

Ingram, K.T., Bueno, F.D., Namuco, O.S., Yabao, E.B., Beyrouty, C.A. 1994. Rice root traits for drought resistance and their genetic variation. In Kirk, G.J.D. (ed.), Rice Roots: Nutrient and Water Use. IRRI. Manila, Philippines. pp. 67-77.

IRGSP 2005. The map-based sequence of the rice genome. Nature 436:793-800.

James Martin, G., Padmanathan, P. K., Subramanian, E. 2007. Identification on suitable rice variety adaptability to aerobic irrigation. J. Agric. Biol. Sci. 2:2.

Kamoshita, A., Wade, L.J., Ali, M.L., Pathan, M.S., Zhang, J., Sarkarung, S., Nguyen, H.T. 2002. Mapping QTLs for root morphology of a rice population adapted to rainfed lowland conditions. Theor. Appl. Genet. 104:880-893.

Kanbar, A., Toorchi, M., Shashidhar, H. E. 2009. Relationship between root and yield morphological characters in rainfed low land rice (Oryza sativa L.). Cereal Res. Commun. 37:261-268.

Kharb, A., Sandhu, N., Jain, S., Jain, R.K. 2015. Linkage mapping of quantitative trait loci for traits promoting aerobic adaptation on chromosome 8 in indica rice (Oryza sativa L.). Rice Genomics Genet. 6:1-5.

Li, Z.C., Mu, P., Li, C.P., Zhang, H.L., Li, Z.K., Gao, Y.M., Wang, X.Q. 2005. QTL mapping of root traits in a doubled haploid population from a cross between upland and low-land japonica rice in three environments. Theor. Appl. Genet. 110:1244-1252.

Manickavelu, A., Nadarajan, N., Ganesh, S.K., Gnanamalar, R.P., Chandra, S., Babu, R. 2006. Drought tolerance in rice: morphological and molecular genetic consideration. Plant Growth Regul. 50:121-138.

Nagaraju, C., Sekhar, M.R., Reddy, K.H., Sudhakar, P. 2013. Correlation between traits and path analysis coefficient for grain yield and other components in rice (Oryza sativa L.) genotypes. Int. J. Appl. Biol. Pharm. 4:137-142.

Parthasarathi, T., Vanitha, K., Lakshamanakumar, P., Kalaiyarasi, D. 2012. Aerobic rice-mitigating water stress for the future climate change. Intl. J. Agron. Plant Prod. 3:241-254.

Qu, Y., Mu, P., Zhang, H., Chen, C.Y., Gao, Y., Tian, Y., Wen, F., Li, Z. 2008. Mapping QTLs of root morphological traits at different growth stages in rice. Genetica 133:187-200. 
Ramekar, R.V., Sa, K.J., Woo, S.Y., Lee, J.K. 2015. Non-parental banding patterns in recombinant inbred line population of maize with SSR markers. Genet. Mol. Res. 14:8420-8430.

Rohlf, F.J. 1993. NTSYS-PC: Numerical taxonomy and multivariate analysis system. Version 1.8. Exeter Software. New York, USA.

Saghai-Maroof, M.A., Soliman, K.M., Jorgensen, R.A., Allard, R.W. 1984. Ribosomal spacer length polymorphism in barley: Mendelian inheritance, chromosomal location and population dynamics. Proc. Natl Acad. Sci. USA 81:8014-8019.

Sandhu, N., Jain, S., Kumar, A., Mehla, B.S., Jain, R. 2013. Genetic variation, linkage mapping of QTL and correlation studies for yield, root, and agronomic traits for aerobic adaptation. BMC Genet. 14:104-119.

Sandhu, N., Torres, R.N., Cruz, M.T.S., Maturan, P.C., Jain, R., Kumar, A., Henry, A. 2014. Traits and QTLs for development of dry direct-seeded rainfed rice varieties. J. Exp. Bot. 66:225-244.

Shen, L., Courtois, B., Mcnally, K.L., Robin, S., Li, Z. 2001. Evaluation of near-isogenic lines of rice introgressed with QTLs for root depth through marker-aided selection. Theor. Appl. Genet. 103:75-83.

Tuong, T.P., Bouman, B.A.M., Mortimer, M. 2005. More rice, less water-integrated approaches for increasing water productivity in irrigated rice-based systems in Asia. Plant Prod. Sci. 8:231-241.

Venuprasad, R., Bool, M.E., Dalid, C.O., Bernier, J., Kumar, A., Atlin, G.N. 2009. Genetic loci responding to two cycles of divergent selection for grain yield under drought stress in a rice breeding population. Euphytica 167:261-269.

Venuprasad, R., Shashidhar, H.E., Hittalmani, S., Hemamalini, G.S. 2002. Tagging quantitative trait loci associated with grain yield and root morphological traits in rice (Oryza sativa L.) under contrasting moisture regimes. Euphytica 128:293-300.

Vikram, P., Mallikarjuna Swami, B.P., Dixit, S., Helaluddin, A., Sta Cruz, M.T., Singh, A.K., Guoyou, Y., Kumar, A. 2012. Bulk segregant analysis: an effective approach for mapping consistent-effect drought grain yield QTL in rice. Field Crop Res. 134:185-192.

Wang, S., Basten, C.J., Zeng, Z.B. 2012. Windows QTL Cartographer 2.5. Department of Statistics, North Carolina State University. Raleigh, NC, USA (http://statgen.ncsu.edu/qtlcart/WQTLCart.htm).

\section{Electronic Supplementary Material (ESM)}

Electronic Supplementary Material (ESM) associated with this article can be found at the website of CRC at http://www.akademiai.com/content/120427/

Electronic Supplementary Table S1. A brief description of the polymorphic microsatellite markers used in the study

Electronic Supplementary Table S2. Phenotypic correlation coefficients among yield and yield components in HKR47 $\times$ MAS26 $F_{2}$ and $F_{3}$ population grown under dry direct-seeded aerobic field conditions

Electronic Supplementary Table S3. Phenotypic correlation coefficients among yield and yield components and root traits in HKR47 $\times$ MAS26 $\mathrm{F}_{3}$ population grown in net house under direct-seeded aerobic conditions

Electronic Supplementary Table S4. Phenotypic correlation coefficients among yield and yield components in $\left(\mathrm{HKR} 47 \times\right.$ MAS26) $\times \mathrm{HKR} 47 \mathrm{BC}_{2} \mathrm{~F}_{2}$ population grown under dry direct-seeded aerobic field conditions

Electronic Supplementary Figure S1. Two-dimensional PCA scaling displaying diversity among HKR $47 \times$ MAS26 $\mathrm{F}_{3}$ plants (grown under aerobic field conditions) and parental genotypes using allelic diversity data at 88 SSR loci

Electronic Supplementary Figure S2. Two-dimensional PCA scaling displaying diversity among HKR47 $\times$ MAS26 $\mathrm{F}_{3}$ plants (grown in net house under aerobic conditions) and parental genotypes using allelic diversity data at 88 SSR loci 